\title{
Manifestation of Remote Sensing Data in Modeling Urban Sprawl Using the SLEUTH Model and Brute Force Calibration: A Case Study of Sana`a City, Yemen.
}

\begin{abstract}
Sana'a the metropolitan capital of Yemen, has experienced rapid spatial growth and uncontrolled development for decades. In the absence of a means to forecast and predict urban growth trends, planning and urban policy decisions have been found wanting. In this study the SLEUTH (Slope, landuse, exclusion, urban extent, transportation and hillshade) model which has been widely and successfully applied in developed countries, has been applied to predict the spatial urban sprawl pattern from 2004-2020 in Sana'a. This was to provide the necessary forecast for better planning and decision making. The model performed well as per the calibration coefficient values. The results showed that there will a $29 \%$ increase in spatial urban sprawl growth during the modeling period. Growth of the sprawl will be mainly at the edges of the urban boundary, there will also be a wide area of scattered urban clusters. Factors that will have major influence on spatial expansion of the city will be diffusion, natural and internal growth, slope (that will hinder spread) and transportation (along which most of the urban sprawl will occur). The study also provides an insight into how the SLEUTH model performs in a poorly planned urban environment as compared to the planned and controlled environment where it has been applied.
\end{abstract}

Keyword: Urban sprawl; SLEUTH model; GIS; Brute force calibration; Remote sensing; Sana`a 